\title{
EVALUATING FACTORS INFLUENCING ASPHALT ROAD CONSTRUCTION QUALITY IN High TEMPERATURE CONDITION (CASE STUDY)
}

\author{
Khlifa S. El atrash* and Gabriel J. Assaf \\ Department of Construction, École de Technologie Supérieure, 1100 Rue Notre-Dame Ouest, Montréal, Canada \\ Date received: 25/12/2018, Date accepted: 23/03/2019 \\ *Corresponding author's email: k_atrch@yahoo.com \\ https://doi.org/10.33736/jcest.1203.2019
}

\begin{abstract}
The assumption of a linear viscoelastic behaviour of asphalt mixes suggests that the response of the material to the inquiry, is the sum of the responses of that material to each elementary petition. However, the construction of asphalt concrete pavements (CAP) is a complicated procedure, including some of climate parameters and material availability. Hot weather environment, such as Libya, has its own challenges and requirements in terms of weather factors, materials, construction equipment, and the availability of materials in each area. However, the condition of some roads seems to be below the required level. Rutting distress is one of the major defects that occur in asphalt pavements in the hot region weather of Libya and has severely influenced drive-ability. Questionnaires and laboratory experiments were conducted for several mixtures at representative temperature and traffic load. In this study, rutting tests were conducted on two different mixtures. The first blind used traditional asphalt bitumen type B (60/70), while another blind was carried out using the Superpave design procedure using asphalt bitumen type performance grade PG (70-10). The questionnaire was sent to tens of engineers and specialists. The interview was carried out with a few others, in which the interview was among the factors that explained the unsatisfactory performance of the asphalt roads in Libya. The results showed that the consideration and improvement of these factors play an important role in improving the characteristics of the road surface, increasing service life, and reducing maintenance costs. ACP should employ asphalt bitumen, which works perfectly in the Libyan environment. Materials properties in asphalt mixture displayed high impact of the pavement performance.
\end{abstract}

Copyright $\odot 2019$ UNIMAS Publisher. This is an open access article distributed under the Creative Commons Attribution-NonCommercial-ShareAlike 4.0 International License which permits unrestricted use, distribution, and reproduction in any medium, provided the original work is properly cited.

Keywords: Asphalt mixtures, consistency, performance, (PG), construction

\subsection{INTRODUCTION}

Libya has an area of $1,759,540 \mathrm{~km}^{2}$. The country serves a highway network with a total length of 83,200 $\mathrm{km}$, of which 47,590 km are paved, as well as more than 100 airports in various cities of Libya [1]. The government has invested billions of USD in road construction. Throughout the world, there are many models of successful construction of asphalt pavements that have been designed to resist load traffic affection in a hot weather or on airport taxiways. However, many elements contribute to improve the goodness of the pavement production. Aggregate angularity, for example, in asphalt hot mixture has a significant impact on rutting resistance [8]. Souza, L., et al. (2012) found that the form, the angularity, and the outer texture of the aggregate strongly influenced the characteristics of asphalt roads. Lack of supervision and no control over the implementation of asphalt roads in the hot weather can lead to inadequate performance of ACP. Approximately most of the newly established asphalt roads in Libya have shown many failures. In fact, many elements can affect the goodness of the asphalt roads during its design life. Besides, there are many elements that may improve the effectiveness of the asphalt roads [6]. These elements are the views of contractors and engineers, related to design and specifications, as well to construction. This can be achieved through survey of engineers and contractors, as well as laboratory work. This study aims to gain better understanding of ACP performance and, so, to improve the properties of asphalt pavement, increase the service life and reduce the cost of maintenance. 


\subsection{BACKGROUND}

Since about $70 \%$ of the total area of Libya located at the hot region, there are a few elements that affect the quality of pavement performance from the design up to the implementation stage. During many years of road construction, authorities have been committed to seek solutions for specific objects. In Libya, the widely used method of road construction is to build the road on backfill materials above the water table level at height of not less than 1.2 meter [3]. Regarding design specifications, the initial set of specification was inserted in 1964 by international experts and was usually based on the experimental of USA and European standers. In fact, these specifications are not always suitable for the environment in Libya. At present, all projects are carried out based on Foreign standards, although there are many models of asphalt mixture failure. In Libya, rutting is the common failure mode, wherein the United States and other countries have adopted the rutting as one of the criteria for designing asphalt pavements [4]. The increased appearance of ruts, especially on road surfaces, can be related to increase in traffic load and tire pressure. The production of asphalt mixtures, the materials selection, and the method of construction should be provided to upgrade the hot mix asphalt (HMA) design in Libya to a level that exceeds traffic load and tire pressure.

\subsection{OBJECTIVES}

The main objectives of this study are as follows: first, to explain some factors that led to unsatisfactory performance of the asphalt roads in Libya. Second, to gain better understanding of ACP performance in order to improve the properties of asphalt mixture in Libya. Finally, this research aims to develop a mix design method of the asphalt mixtures locally using a suitable material to the Libyan environment, such as the asphalt binder PG 70-10.

\subsection{METHODOLOGY OF RESEARCH}

Rutting is one of the major failures that occur in asphalt pavements in Libya, while most countries have adopted the rutting as one of the criteria for designing asphalt pavements. In this paper, two different asphalt mixtures were tested by rutting machine test. These mixtures have used same materials of aggregate and filler, and then, used two different asphalt binders, one to each mixture. The first mixture was prepared by using a traditional mix design method and asphalt binder B (60/70), while the second one was prepared by using Superpave mix design method and asphalt binder PG (70-10). The survey questioner was designed to show elements that affected the quality and the performance of the asphalt roads in Libya. The form of the questionnaire was developed based on an analysis of relevant literature and several interviews with engineers and contractors. The questionnaire consisted of several questions regarding the impact of performance of the road surface. The questions included demographic details of the respondents, types of asphalt binder, upgrading of asphalt mix design methods, scarcity of data collection, contractor manpower and equipment capability, and construction control. In hot weather such as that in Libya, there are many other factors that can influence the behaviour of the pavement; however, these factors were proposed by contractors and engineers during the interviews. These aspects were explained and evaluated by their impact. The respondents chose one of four possible responses, standing for different degrees of effect, on a scale of 1 to 4. The answer 4, EE: Major Effect; 3, E: Effect; 2, LE: Low Effect; 1, NE: No Effect means that the factor did not affect (NE); 1, low effect (LE); 2, effect, (E); 3 and 4, Major effect (EE). The questionnaires were analysed, and the influence indicator was calculated for each factor using the following equation: 


$$
\text { Influence Indicator }=\sum_{i=1}^{4}=\left(\frac{X i \times Y i}{N}\right) \times \frac{100}{4}
$$

where $X i=$ weight for each participant; $i=0,1,2,3$

and 4 ; and $Y i=$ frequency of the $i$ th response.

These elements greatly improved pavement performance and durability, apart from lowering maintenance costs.

\subsection{FACTORS THAT INFLUENCE PAVEMENT PROPERTIES}

Table 1 illustrates the results of the survey and presents the factors that affect the characteristics of the pavement. Six factors have been listed with their level of influence in the following paragraphs.

Table 1 Factors affecting pavement performance in Libya

\begin{tabular}{lc}
\hline \hline \multicolumn{1}{c}{ Factor } & Inf. Indicator \\
\hline Owner Name and Background & $87 \%$ \\
Type of Asphalt Binder & $93 \%$ \\
Upgrading of Asphalt Mix Design Methods & $84 \%$ \\
Scarcity of Data Collection & $92 \%$ \\
Contractor manpower and equipment capability & $80 \%$ \\
Construction Control. & $78 \%$
\end{tabular}

\subsection{OWNER NAME AND BACKGROUND}

Although the quality of road performance has direct functions of material selection and mixture design, owner experience and technical staff have high impact on the final product. Some important elements of successful construction process are human resource, equipment, and owner experience. The first factor that influences the qualification is the inspection team of the owner and the contractor. It has an impact of 87\%. Qualifications and experience inspection groups are important for a perfect construction. The supervision team must ensure compliance with the drawings and specifications to ensure that the construction process meets the requirements of the project. The supervising team should be familiar with all the details of the project and its functions. Otherwise, the pavement may not meet the minimum requirement as a result of poor level of productivity [5]; [6]. Almost all labourers in Libya are unqualified or semi-qualified and they come from either Africa or the Third World. Since the quality and the performance of the road pavement is a function in the materials used and the construction process, a shortage of experienced owner or contractor may lead to inadequate control of the process, which leads to poor quality work.

\subsection{TYPE OF ASPHALT BINDER}

In Libya until to this date, asphalt binder that is used in the preparation of asphalt mixture is selected based on a penetration system, which have several limitations. The viscosity grading system is based on binder viscosity at 60 degrees Celsius. Viscosity grading is related to the consistency of the binder at a specific temperature and not directly related to its performance throughout the anticipated life of the pavement. As a result, it does not mandate for viscosity measurements and therefore, it is difficult to set up the correct HAM [7]. On the other hand, in recent years, the Strategic Research Programs in High Technology 
(SHRP) has developed new criteria for the selection of asphalt binder, known as a Performance Grade system (PG), to overcome certain limitations. The concept of PG is based on the rheological theory that the properties of asphalt binder should be related to the climatic conditions under which it should be used. The engineering properties that are believed to be associated with the expected performance (maximum pavement temperature of seven days and one-day minimum pavement temperature) are featured in the specifications of the PG binder [2].

\subsection{UPGRADING OF ASPHALT MIX DESIGN METHODS}

Most developing countries use volumetric analysis in designing asphalt mixtures, which can also be upgraded in hot arid weather. However, to be effective, it should include some proper aspects, which are materials, environment, and method of construction. Lack of database, not allocating a budget, and limited scientific research in paving asphalt roads appear to be some factors. The use of multiple specifications by foreign companies that failed to take into consideration the climatic condition and the resources of local materials are also part of the limiting factors. All these lead to premature permanent deformation, unsuitable asphalt mixtures, and the inability to develop a mix design method locally. Almadwi and Assaf (2017) asserted that "the performance of PG70-10 mixes was found superior to the mixes using B 60/70. The results of the Super Gyratory Compactor tests were found to be a better indicator of performance than those given by Marshall Stability tests." The existence of a database, local specifications, and the encouragement of scientific research can inevitably lead to the development of the design of asphalt mixtures in the region.

\subsection{SCARCITY OF DATA COLLECTION}

Engineers and contractors in Libya are faced with the problems of building a pavement for a desert or sand dune, (hot desert area), typically found in North Africa and the Arabian areas. In addition, the prediction of traffic growth in Libya is quite difficult due to many reasons, such as inaccessibility of annual road traffic counts by road agencies. The fluctuation in the economic situation is very high. In Libya, there is no development strategy, plans for roads, services, sources of fund, and land use are not available. The construction of HMA is a complicated process, including many critical factors, which can affect the quality of the asphalt pavement and are not considered at mix design [8]. Recently, built pavements in Libya showed poor quality of pavement distresses, namely rutting, shoving, and depressions within the first few years of operation.

\subsection{CONTRACTOR MANPOWER AND EQUIPMENT CAPABILITY}

Throughout the execution of asphalt roads, a few elements may affect the quality of pavement performance from the design up to the implementation stage. Placement, testing, monitoring aggregate gradient, asphalt bitumen content, mixing temperature, compaction temperature, and compaction method are critical factors that can affect the final product quality [8]. Aggregate (gradation, form, and type) has an impact of $80 \%$. In Libya, there are three different regions of aggregate for road construction. In the north region, there is qualitative aggregate, while in the middle region there is average quality score of aggregate, and rare quality in the southern region. As these regions cover various traffic conditions, climate, and subgrade layer, a change in these factors can lead to diversity in pavement properties in these regions, especially if the same standard specifications are used in asphalt pavement construction projects throughout the country. In addition, the lack of good quality materials and high temperature in some areas can lead to higher 
costs. In fact, suitable pavement construction depends on the selection of materials, proper techniques and equipment, and careful attention to details in the implementation process [4].

\subsection{CONSTRUCTION CONTROL}

Monitoring of mix design (aggregate skeleton, OBC, mixing temperature and compaction method) has an impact of $78 \%$. The mixing procedure can have a significant effect on the viscosity of asphalt binder and the behaviour of the final product during the paving process. Controlling the amount of asphalt and mixing temperature during mix design procedure are very important for producing an acceptable mixture. This reduces the aging of the asphalt binder (oxidation) and giving a homogeneous coated mixture, since the proper content of asphalt is critical to obtain the desired content of voids in the compacted mixture. The amount of air voids affects pavement properties, such as durability, flexibility, stability, and susceptibility to moisture damage. A change in the content of asphalt can lead either to a dry mixture, which can lead to premature ravelling and cracking, or in rich mixtures that can lead to permanent deformation [9].

\subsection{RESULT OF RUTTING TEST AND QUESTIONNAIRE SURVEY}

In this experiment, Table 2 shows the aggregate gradation used in these mixes, wherein specimens were tested by using bitumen binder B60/70 and the other specimens by bitumen binder PG 70-10. The obtained results are presented in Tables 3(a) and 3(b) and illustrated in Figure 1. From the questionnaire survey, factors affecting the quality of the road surface were found and evaluated on a scale, depending on their impact. The obtained results of the questionnaire survey are presented in Table 1.

Table 2 Aggregate gradation for laboratory mix design

\begin{tabular}{cccc}
\hline \hline Sieve size mm & $\begin{array}{c}\text { \%Lower } \\
\text { Limit }\end{array}$ & $\begin{array}{c}\text { \%Upper } \\
\text { Limit }\end{array}$ & \% Passing \\
\hline 28 & 100 & 100 & 100 \\
20 & 95 & 100 & 98 \\
14 & 67 & 90 & 85 \\
10 & 52 & 75 & 68 \\
5 & 34 & 55 & 44 \\
2.5 & 24 & 45 & 26.8 \\
1.25 & 16 & 39 & 17.6 \\
0.63 & 9 & 31 & 13.3 \\
0.31 & 6 & 23 & 10.8 \\
0.16 & 4 & 15 & 8.6 \\
0.08 & 3 & 8 & 5.88
\end{tabular}

\subsection{SUMMARY AND CONCLUSION}

Many aspects have contributed to increase the productivity. Road contractors were surveyed for factors that control the performance of the asphalt roads. Factors affecting the quality of the road surface were found and evaluated on a scale, depending on their impact. Eq. (1) shows how to calculate the effect of each of these factors. The results obtained from the questionnaire and laboratory experiments showed that each area has its own characteristics and requirements in the asphalt mix design. Libya is faced with the problems of building asphalt roads for hot weather environment. The questionnaire survey concluded that some factors have more impact on the pavement performance, which are owner experience and technical 
staff, asphalt characteristics, updating and development of asphalt mix design methods, lack of data collection by authorization agency, construction and compaction process, as well as mentoring and controlling mixing procedure. Appendix shows an example of the questionnaire survey. Rutting is one of the main distresses that occur in asphalt pavements in Libyan weather and badly affect the ride-ability. This study showed that in rutting test, most of the permanent deformation occurred in the upper four inches of HMA. Figure (1), Table 3 and Table 4 show that the mixes using the asphalt binder (PG 70-10) displayed better resistance to rutting than the mixes using the asphalt binder (B 60/70). Mixes with asphalt binder PG (70-10) and compacted with SGC are more superior to mixes with asphalt binder (60/70) for all stages of the tests. The use of a highly sensitive asphalt binder to high-temperature changes in Libya is highly recommended. This research leads to better understanding of ACP performance to improve the properties of asphalt pavement, to increase the service life, and to reduce the cost of maintenance.

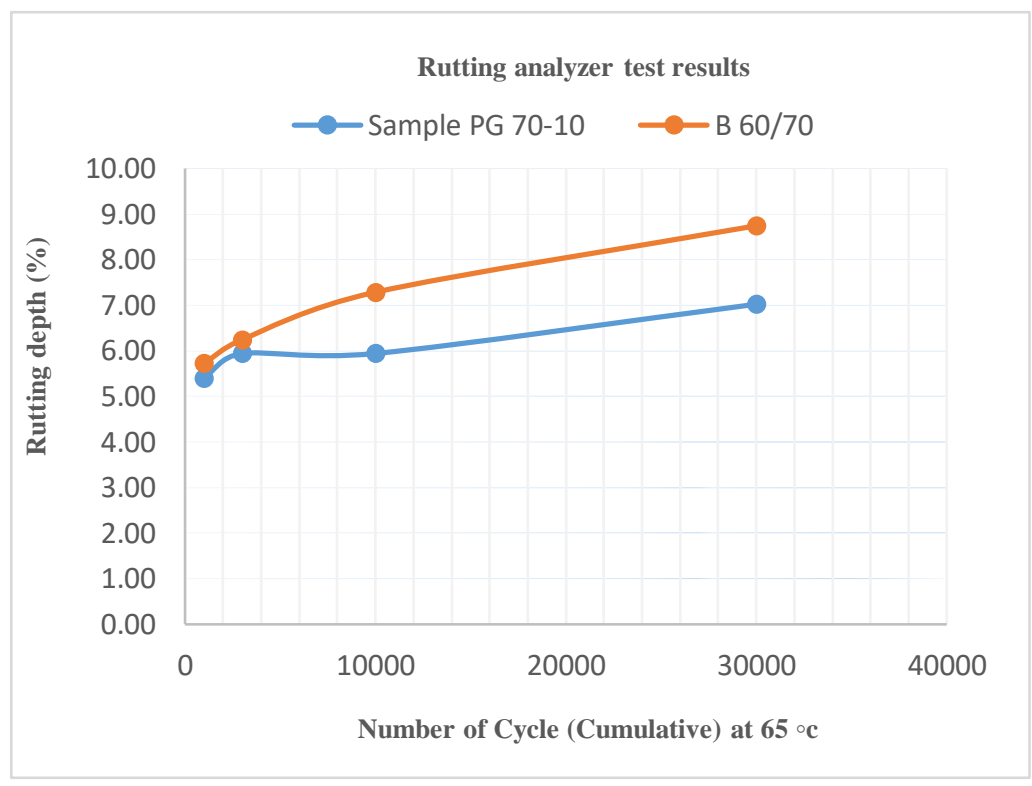

Figure 1 Rutting depth of two different mixtures

Table 3 Rutting analyzer test results

\begin{tabular}{ccc}
\hline \hline No of Cycles & $\begin{array}{c}\text { \% Rut of Samples with Bi- } \\
\text { tumen PG70-10 }\end{array}$ & $\begin{array}{c}\text { \% Rut of Samples } \\
\text { with Bitumen B60/70 }\end{array}$ \\
\hline 1000 & 5.4 & 5.73 \\
3000 & 5.94 & 6.25 \\
10000 & 5.94 & 7.29 \\
30000 & 7.02 & 8.74
\end{tabular}


Table 4 Rutting test result for whole cycled

\begin{tabular}{|c|c|c|c|c|c|c|c|c|}
\hline \multicolumn{3}{|c|}{ SPECIMEN DESCRIPTION } & \multirow{2}{*}{$\begin{array}{c}\text { Cold } \\
\text { CyCle } \\
1000\end{array}$} & \multicolumn{4}{|c|}{$\begin{array}{c}\text { Number OF CyCLES (CUMULA- } \\
\text { TIVE) At } 65^{\circ} \mathrm{C}\end{array}$} & \multirow{2}{*}{$\begin{array}{c}\text { RUTTING AT } \\
30000 \text { CY- } \\
\text { CLES (MM) }\end{array}$} \\
\hline $\begin{array}{l}\text { BINDER } \\
\text { TYPE }\end{array}$ & $\begin{array}{l}\text { SAM- } \\
\text { PLE No }\end{array}$ & $\begin{array}{l}\text { SAMPLE } \\
\text { HEIGHT }\end{array}$ & & 1000 & 3000 & 10000 & 30000 & \\
\hline \multirow[t]{2}{*}{ PG 70-10 } & SI & 107.65 & 0.025 & 0.05 & 0.06 & 0.06 & 0.07 & 6.99 \\
\hline & SII & 108.45 & 0.035 & 0.05 & 0.05 & 0.05 & 0.06 & 6.51 \\
\hline \multicolumn{2}{|c|}{ AvERAGE } & 108.05 & 0.03 & 0.05 & 0.05 & 0.055 & 0.065 & 6.75 \\
\hline \multirow[t]{2}{*}{$\mathrm{B}(60 / 70)$} & SI & 104.45 & 0.02 & 0.06 & 0.06 & 0.07 & 0.085 & 7.83 \\
\hline & SII & 103.75 & 0.015 & 0.05 & 0.06 & 0.07 & 0.083 & 7.57 \\
\hline \multicolumn{2}{|c|}{ AvERAGE } & 104.1 & 0.017 & 0.05 & 0.06 & 0.07 & 0.084 & 7.7 \\
\hline
\end{tabular}

\subsection{ACKNOWLEDGEMENT}

Deepest greetings to all those who have supported this research, especially Professor G. Assaf. I would like to thank ETS "École de Technologie Supérieure, Université de Québec, Canada," for providing the laboratory equipment for this research. Thanks to the technical staff of the bitumen and soil laboratory at ETS. Finally, thanks to my colleagues, Talal and Haba from the Construction Department, who gave insight and ability that greatly aided the research.

\section{REFERENCES}

[1] A. Goldschmidt Jr, A concise history of the Middle East. Routledge, 2018.

[2] F. S. Almadwi and G. J. Assaf, "Performance Testing of Paving Mixes for Libya's Hot and Arid Conditions, Using Marshall Stability and SUPERPAVE Gyratory Compactor Methods," in International Congress and Exhibition" Sustainable Civil Infrastructures: Innovative Infrastructure Geotechnology", 2017, pp. 313-323.

[3] Z. Guo, J. Yi, S. Xie, J. Chu, and D. Feng, "Study on the Influential Factors of Noise Characteristics in DenseGraded Asphalt Mixtures and Field Asphalt Pavements," Shock Vib., vol. 2018, 2018.

[4] R. L. Baus and N. R. Stires, "Mechanistic-empirical pavement design guide implementation," University of South Carolina. Dept. of Civil \& Environmental Engineering, 2010.

[5] S. Hussan, M. A. Kamal, I. Hafeez, D. Farooq, N. Ahmad, and S. Khanzada, "Statistical evaluation of factors affecting the laboratory rutting susceptibility of asphalt mixtures," Int. J. Pavement Eng., vol. 20, no. 4, pp. 402-416, 2019.

[6] A. Y. Akal, A. E. A. El-Maaty, and S. El-Hamrawy, "Mapping the Causes of Time, Cost Overruns and Quality Shortfall in Egyptian Public Highway Projects," Eur. Bus. Manag., vol. 3, no. 6, p. 120, 2017.

[7] M. E. Abdullah, K. A. Zamhari, M. R. Hainin, E. A. Oluwasola, N. I. M. Yusoff, and N. A. Hassan, "High temperature characteristics of warm mix asphalt mixtures with nanoclay and chemical warm mix asphalt modified binders," J. Clean. Prod., vol. 122, pp. 326-334, 2016.

[8] L. Sun, Structural Behavior of Asphalt Pavements: Intergrated Analysis and Design of Conventional and Heavy Duty Asphalt Pavement. Butterworth-Heinemann, 2016.

[9] Q. Xu and G. K. Chang, "Adaptive quality control and acceptance of pavement material density for intelligent road construction,” Autom. Constr., vol. 62, pp. 78-88, 2016. 